\title{
Nutrients Release from a Novel Gel-Based Slow/Controlled Release Fertilizer
}

\author{
H. Ding, ${ }^{1}$ Y. S. Zhang, ${ }^{1}$ W. H. Li, ${ }^{1}$ X. Z. Zheng, ${ }^{1}$ M. K. Wang, ${ }^{1}$ L. N. Tang, ${ }^{2}$ and D. L. Chen ${ }^{3}$ \\ ${ }^{1}$ Institute of Soil and Fertilizer, Fujian Academy of Agricultural Sciences, Fuzhou 350013, China \\ ${ }^{2}$ Tobacco and Agricultural Research Institute, Fujian Municipal Tobacco Company, Fuzhou 350003, China \\ ${ }^{3}$ Faculty of Veterinary and Agricultural Sciences, The University of Melbourne, Melbourne, VIC 3010, Australia \\ Correspondence should be addressed to H. Ding; hongding@china.com
}

Received 7 March 2016; Accepted 17 April 2016

Academic Editor: Marco Trevisan

Copyright (C) 2016 H. Ding et al. This is an open access article distributed under the Creative Commons Attribution License, which permits unrestricted use, distribution, and reproduction in any medium, provided the original work is properly cited.

A novel gel-based slow/controlled release fertilizer (G-CRF) was developed, which was produced by combining various natural, seminatural, and/or synthetic organic macromolecule materials and natural inorganic mineral with conventional NPK fertilizers. Its nutrient release characteristics were studied to compare with conventional fertilizers through the soil column leaching method. The influences of soil factors, including temperature, $\mathrm{pH}$, water, and nutrient contents in the G-CRF on nutrient release, were also investigated through soil-water incubation method. These results indicated that the G-CRF had better effect on controlling release of N, P, and $\mathrm{K}$ nutrients, and the effect was more efficient when soil-water content was lower than $45 \%(\mathrm{w} / \mathrm{w})$, temperature was below $35^{\circ} \mathrm{C}$, and soil $\mathrm{pH}$ was in the range from weak acid to neutral. In addition, considering the effect of controlling nutrient release and cost of the materials in the G-CRF, it is recommended that the most feasible NPK nutrient contents in the G-CRF ranged from 30 to $35 \%$.

\section{Introduction}

It is commonly thought that development of slow/controlled release fertilizers (SRFs/CRFs) was a better method to solve low nutrient use efficiency (NUE) of fertilizer and reduce the impact of fertilizer on environments [1]. In recent years, many studies have focused on development of SRFs/CRFs which is formulated to supply nutrients to plants and in quantities needed for proper growth. Application of SRFs/CRFs has many advantages in economic, better plant physiology index, and environmental aspects $[2,3]$. Thus, many kinds of SRFs/CRFs have been developed worldwide, which could be mainly divided into three types according to nutrient release mechanisms of these fertilizers. The first one was the coated CRFs in which a granule of fertilizer is encapsulated; the second is a system where the active component is dispersed in a polymer matrix (i.e., matrix CRFs); another distinct category of the CRFs is systems in which there is no physical barrier in the form of a polymer material; such fertilizers include inorganic materials of low solubility (e.g., ammonium and metallic phosphates) and chemically or biologically degradable materials of low solubility (e.g., urea-formaldehyde condensates, oxamides, and diurea of $\mathrm{N}$ fertilizers) [4].

Most studies quoted in the literatures on the CRFs were coated fertilizers, the production and consumption of which were the fastest growing type among the manufactured CRFs [5]. Although coated CRFs display a lot of advantages, it has also shown some defects, such as complex processing technology, higher material price, unclear impact factors on nutrient release [6], and potential pollution of the residual material left in soil after the decomposition of CRFs. The high price is the main factor which is restricted to the usage of CRFs in commercial crops, flowers, and lawns. As a kind of matrix CRF (gel-based matrix CRFs), G-CRFs were produced through compound hydrophilic polymers. G-CRFs were composited with multikinds of natural, seminatural, and/or synthetic macromolecule materials mixed with the conventional fertilizers to control the nutrient release and improve the NUE [7, 8], and G-CRF had better controlled capability on release of nutrients and was more economic in prices [9]. Though the gel-based matrix fertilizers were less common in practice than the coated fertilizers and were 
still under development [2], with the characteristics of being cheaper price, being more degradable, and being friendly to environment. Due to its advantages, the G-CRFs is in line with the future development directions of controlled release fertilizers.

In view of the following criteria of the above macromolecule materials, the G-CRFs materials should be (1) natural, seminatural, or compound hydrophilic macromolecule polymers, biodegradable, and friendly to environment; (2) easily obtained and cheaper; (3) good performance in nutrient control. Thus, a novel gel-based CRF was developed by treating some natural, seminatural, and synthetic organic macromolecule materials as the gel-based carrier and mixed with conventional fertilizers, and these control release materials used in G-CRF accorded with the above goals, most of which were selected from processing of agricultural products and natural renewable resources and conducted a pot experiment to test the effect of the G-CRF on improving NUE by ${ }^{15} \mathrm{~N}$-labeled method [10], as well as field experiments on yields of different crops [11, 12]. In this study, in-door incubation experiments were employed to test the nutrient release characteristics of the G-CRF and the impact factors to nutrient release, which would offer valuable references for the further development and application of the G-CRFs.

Based on different types of CRF, the different methods to evaluate the controlled effect of CRFs on nutrient release also should be selected for measure of nutrient release rate from different CRFs. In fact, some methods have been adopted for these purposes, but a uniform one which can be widely applied to each type of CRF had not been put forward. At present, in-door experimental method was preferred for the coated fertilizer, and measuring of the nutrient dissolved release rates in water and soil leaching were the main methods [13]. The control release effect of urea-formaldehyde fertilizer was evaluated by measuring the cold-water insoluble $\mathrm{N}$ [14]. Dissolved release rate in water was faster and the method was easy to operate, but for the simplex condition of water, it was significantly different from soil which has more complex physical-chemical characteristics. Thus, evaluating the nutrient release characteristics of fertilizer in water condition was not enough. The soil leaching method was more close to the field condition, though it needed more time. In this study, soil column leaching and soil-water incubation methods were employed to evaluate the nutrient release characteristics of the gel-based CRFs.

\section{Materials and Methods}

2.1. Experimental Materials. The G-CRFs made from gelbased barrier materials and conventional fertilizers were used in this experiment. The carrier materials were composed by organic macromolecule compounds which included pregelatinized starch $(4 \%, \mathrm{w} / \mathrm{w}$, the same below, purchased from Liaocheng A-Hua Pharmaceutical Company Ltd., Liaocheng, China), lignosulfonate (13.3\%, Jiangmen Sugarcane Chemical Company Ltd., Jiangmen, China), tung oil (1.5\%, Xiangshan Tung Oil Processing Plant, Jian, China), disproportionated rosin (4\%, Wuzhou Pine Chemicals Ltd., Wuzhou, China), carboxymethyl cellulose (4\%, Airui Cellulose, Shijiazhuang,
China), and polyvinyl acetate (4\%, Shantou Xilong Chemical Factory, Shantou, China), and the materials also contained a natural inorganic mineral attapulgite (14.6\%, Tianyu Mineral Products Factory, Mingguang, China). The conventional fertilizers included urea $\left(\left(\mathrm{NH}_{2}\right)_{2} \mathrm{CO}, \mathrm{N} 46 \%, 23.9 \%\right.$, w/w), diammonium phosphate $\left(\left(\mathrm{NH}_{3}\right)_{2} \mathrm{HPO}_{4}, \mathrm{~N} 18 \%, \mathrm{P}_{2} \mathrm{O}_{5} 46 \%\right.$, $17.4 \%, \mathrm{w} / \mathrm{w})$, and potassium chloride $\left(\mathrm{KCl}, \mathrm{K}_{2} \mathrm{O} 60 \%, 13.3 \%\right.$, $\mathrm{w} / \mathrm{w})$. Based on above material composites and weight percentages, the nutrient proportions of $\mathrm{N}: \mathrm{P}_{2} \mathrm{O}_{5}: \mathrm{K}_{2} \mathrm{O}$ in the GCRF were designed as $14: 8: 8$.

The production process of the G-CRF was described as follows. Firstly, powdered chemical phosphorus and potassium fertilizers, $\left(\mathrm{NH}_{4}\right)_{2} \mathrm{HPO}_{4}$ and $\mathrm{KCl}$, were used and mixed with powdered pregelatinized starch, lignosulfonate, carboxymethyl cellulose, and attapulgite; then $10 \%(\mathrm{w} / \mathrm{w})$ water was added into the mixture and stirred fully. Secondly, (1) polyvinyl acetate was added into the urea solution, then heated $\left(135^{\circ} \mathrm{C}\right)$, and dissolved into liquid; (2) disproportionated rosin was added into tung oil and heated $\left(>130^{\circ} \mathrm{C}\right)$ into liquid. Finally, the two liquids ((1) and (2)) were poured into the above mixture and it was continually stirred. The whole mixture becomes viscous complexes, which could be put into the granulator to produce $3 \mathrm{~mm}$ particle size of G$\mathrm{CRF}$ granules and dried as the G-CRF granules.

2.2. Nutrients Released Rates of G-CRF. The nutrient release characteristics of the G-CRF and mixed conventional NPK fertilizers were compared using soil column leaching method. A paddy soil derived from red soil with clay loam texture was collected from 0 to $20 \mathrm{~cm}$ depth of surface rice-planted field at Baisha Town, suburban district of Fuzhou, Fujian province, China. The soil type was classified as oxisols, in which classification Kandiudox was derived from red sandy rock-bed and classified as gleyed red sand paddy soil (Soil Survey Staff 2010). Surface soils were air-dried, ground, and passed through a $1 \mathrm{~mm}$ mesh. The physicochemical properties of surface red paddy soil are OM 3.2\%, TN $2.0 \mathrm{~g} \cdot \mathrm{kg}^{-1}$, available $\mathrm{N} 154.5 \mathrm{mg} \mathrm{kg}^{-1}$, available $\mathrm{P} 10.2 \mathrm{mg} \mathrm{kg}$, available K $52.7 \mathrm{mg} \mathrm{kg}^{-1}$, pH 5.7, and CEC $10.7 \mathrm{cmol} \mathrm{kg}^{-1}$. The soil physical and chemical propertieswere analyzed usingthe methods of Jackson [15].

Three different fertilizer treatments in the experiment were designed as control (no fertilizer in carrier material, CK), conventional fertilizers (CF), and G-CRF with 4 replications for each treatment. In the $\mathrm{CF}$ treatment $3.55 \mathrm{~g}\left(\mathrm{NH}_{2}\right)_{2} \mathrm{CO}, 2.61 \mathrm{~g}\left(\mathrm{NH}_{3}\right)_{2} \mathrm{HPO}_{4}$, and $2.00 \mathrm{~g} \mathrm{KCl}$ were applied in each soil column, respectively, while in the GCRF treatment $15.00 \mathrm{~g} \mathrm{G-CRF}$ per soil column was applied. Thus, the total amounts $(2.1,1.2$, and $1.2 \mathrm{~g}$, resp.) and ratios $(1: 0.57: 0.57)$ of $\mathrm{N}, \mathrm{P}_{2} \mathrm{O}_{5}$, and $\mathrm{K}_{2} \mathrm{O}$ nutrients in each soil column were the same in CF and G-CRF treatments.

At first, $200 \mathrm{~g}$ quartz grain (cleaned by the dilute hydrochloric acid) was filled in the bottom of each polyvinyl chloride (PVC) column with an inner diameter of $10 \mathrm{~cm}$ and a length of $50 \mathrm{~cm}$ (about $3 \mathrm{~cm}$ thick); then $2 \mathrm{~kg}$ airdried soil mixed with different fertilizers was packed in the column and compacted by a magnetic vibrator. The soil bulk density in a column was $1.33 \mathrm{~g} \mathrm{~cm}^{-3}$. The flow rate was 
adjusted with mechanical vacuum extractor. Flow velocity observed from average saturated hydraulic conductivity of soil was $1.0 \mathrm{~cm} \mathrm{~h}^{-1}$. Pore volume of solution was calculated from saturated water hydraulic conductivity, porosity, and total volume of soil in column. Detailed procedure followed that adopted by Liu et al. [16] and finally was followed by another $200 \mathrm{~g}$ cleaned quartz grain, which was on the top of each soil column in order to prevent the destroying of upper soil layer. A funnel and plastic bottle was played under each soil column to collect the leaching solution. Before the start of the experiment, $1050 \mathrm{~mL}$ of double deionized water (DDW) was added into each soil column, which made the soil saturating and gravitational water leak out, and the top of column was closed with plastic film to avoid water evaporation from the column. Before each sampling, $50 \mathrm{~mL}$ of DDW was added in each soil column, and the leaching solution from soil columns was collected in plastic bottle from 1 to 17 pore volumes after starting the experiment, then measured volume of the leachate, and determined the N, P, and $\mathrm{K}$ concentrations in the leachate immediately. The results were calculated as follows:

$$
t(\%)=\frac{\left(f_{t}-c_{t}\right)}{M} \times 100,
$$

where $t$ is nutrient $\left(\mathrm{N}\right.$ or $\mathrm{P}_{2} \mathrm{O}_{5}$ or $\mathrm{K}_{2} \mathrm{O}$, the same below) release rate of fertilizer in each pore volume, $f_{t}$ is nutrient release amount in certain pore volume from the treatments in which fertilizer was applied, $c_{t}$ is nutrient release amount in certain pore volume from the treatment in which no fertilizer was applied, and $M$ is nutrient amount in the fertilizers:

$$
T(\%)=\frac{\left(F_{t}-C_{t}\right)}{M} \times 100,
$$

where $T$ is cumulated nutrient release rate of fertilizer, $F_{t}$ is cumulated nutrient amount released from the treatments in which fertilizer was applied from the beginning to certain pore volume, and $C_{t}$ is cumulated nutrient amount released from the treatment in which no fertilizer was applied from the beginning to certain pore volume.

\subsection{Effects of Impact Factors on the Nutrients Release. In order} to investigate the effect of soil moisture on the nutrient release from the G-CRF, the experiment was designed as follows. One hundred grams of air-dried soil mixed well with $10 \mathrm{~g} \mathrm{G}$ CRF was filled in a plastic bottle with a hole at bottom which was wrapped with nylon net (100 meshes) and blocked by a cap tightened; all bottles were fixed on iron shelf and then played a glass Erlenmeyer flask under the bottle to collect the solution and remove the cap; all solution would flow out from the bottle. The soil moistures were designed as 6 levels of 15 , $25,35,45,75$, and $105 \%(\mathrm{w} / \mathrm{w})$ by adding different quantity of water; top of the bottle was sealed with plastics film for avoiding water evaporation. The solution samples were taken in $1,2,4,6,9,12$, and 15 days after starting the experiment. Before each time sampling, $70 \mathrm{~mL}$ of DDW was added in the soil in each treatment with 4 replications for getting the solution, because the soils in low moisture treatments were unsaturated. The soluble $\mathrm{N}, \mathrm{P}$, and $\mathrm{K}$ in the solution were measured, and the nutrient release rate was calculated by the following formula:

$$
\text { Nutrient release rate }(\%)=\frac{C * V}{M} \times 100,
$$

where $C$ is nutrient concentration in leachate $\left(\mathrm{g} \mathrm{mL}^{-1}\right), V$ is leachate volume in each sampling $(\mathrm{mL})$, and $M$ is nutrient amount in fertilizer (g).

The experimental design to investigate the effect of temperature on nutrient release from the G-CRF was carried out as follows. One hundred grams of air-dried soil mixed with $10 \mathrm{~g}$ G-CRF was filled in a $250 \mathrm{~mL}$ wild-mouth bottle, and then the bottles were taken into constant temperature incubator after adding $200 \mathrm{~mL}$ of DDW. The incubation temperatures were set at $5,15,25,35,45$, and $55^{\circ} \mathrm{C}$, with 4 replications for each treatment. The solution samples were taken in $1,2,4,6,9,12$, and 15 days since beginning of incubation. At each time of sampling, the whole solution in the bottle was filtered through the qualitative filter paper for determining $\mathrm{N}, \mathrm{P}$, and $\mathrm{K}$ contents. The nutrient release rate was calculated by the following formula:

$$
\begin{aligned}
& \text { Nutrient release rate }(\%) \\
& =\frac{\text { nutrient concentration in solution }\left(\mathrm{g} \mathrm{mL}^{-1}\right) * 200 \mathrm{~mL}}{\text { nutrient content in fertilizer }(\mathrm{g})} \\
& \quad \times 100 \text {. }
\end{aligned}
$$

The effect of soil $\mathrm{pH}$ on the nutrient release from GCRF was also studied through incubation experiment. One hundred grams of air-dried soil mixed with $10 \mathrm{~g}$ G-CRF was filled in $250 \mathrm{~mL}$ wild-mouth bottle. The experiment was designed as 6 soil $\mathrm{pH}$ levels with 4 replications. In order to prepare the soils with different $\mathrm{pH}$ levels, $200 \mathrm{~mL}$ of DDW adjusted the $\mathrm{pH}$ to $4,5,6,7,8$, and 9 with $\mathrm{HCl}$ or $\mathrm{NaOH}$ solution and were added into the soils, respectively. The experiment was incubated at $25^{\circ} \mathrm{C}$. The solution samples were taken in $1,2,4,6,9,12$, and 15 days since the beginning of incubation, respectively. At each time of sampling, the whole solution in the bottle was filtered through the qualitative filter paper for determining $\mathrm{N}, \mathrm{P}$, and $\mathrm{K}$ contents. The nutrient determining and release rate calculating were done the same as in temperature experiment.

The effects of nutrient contents in the G-CRFs on nutrient release set 5 nutrient content levels as $25\left(\mathrm{~N}-\mathrm{P}_{2} \mathrm{O}_{5}-\mathrm{K}_{2} \mathrm{O}=12\right.$ 7-6), 30 (14-8-8), 35 (17-9-9), 40 (18-11-11), and 45\% (21-12-12), the NPK nutrient ratios in these fertilizers all were equal, and the gel-based carrier material amounts used in the G-CRFs would decrease or increase according to their proportion with variation of nutrient contents in the G-CRFs. Five kinds of GCRF all were granulated, but it was difficult to form fertilizer granule when the NPK nutrient content exceeded 50\%. Ten grams of each G-CRF was mixed with $100 \mathrm{~g}$ air-dried soil and filled in a $250 \mathrm{~mL}$ wild-mouth bottle, and then $200 \mathrm{~mL}$ of DDW was added into the bottle which was incubated in the constant temperature $\left(25^{\circ} \mathrm{C}\right)$ incubator. The solution samples were taken in $1,2,4,6,9,12$, and 15 days since beginning of incubation, respectively. At each time of sampling, the whole 


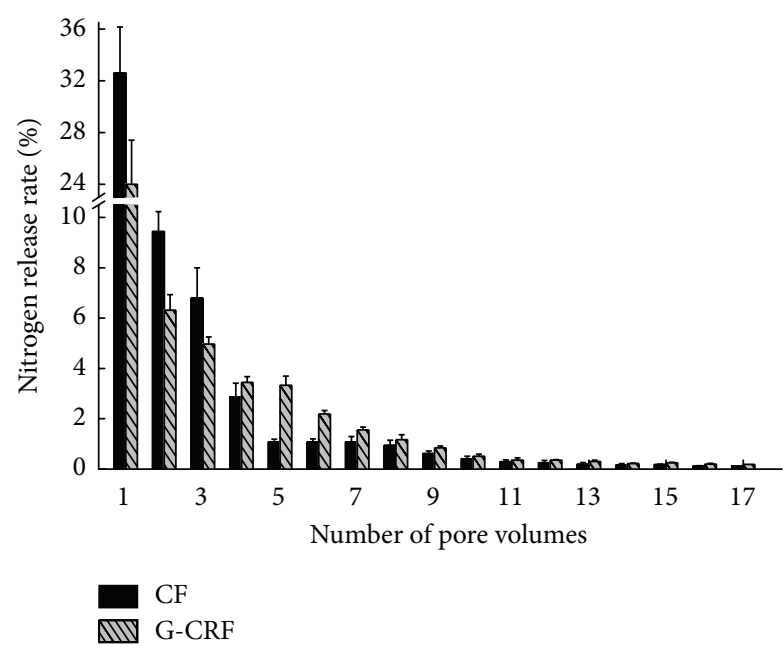

(a)

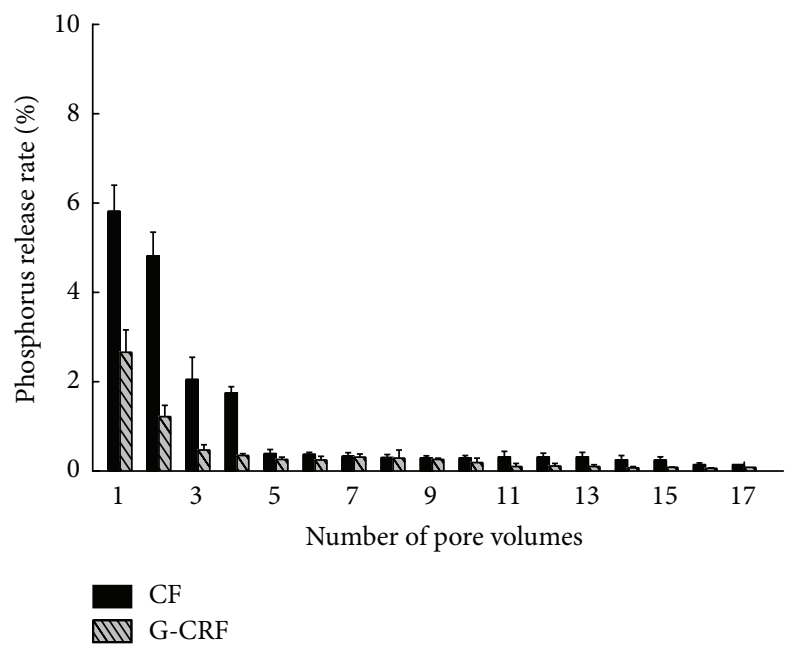

(b)

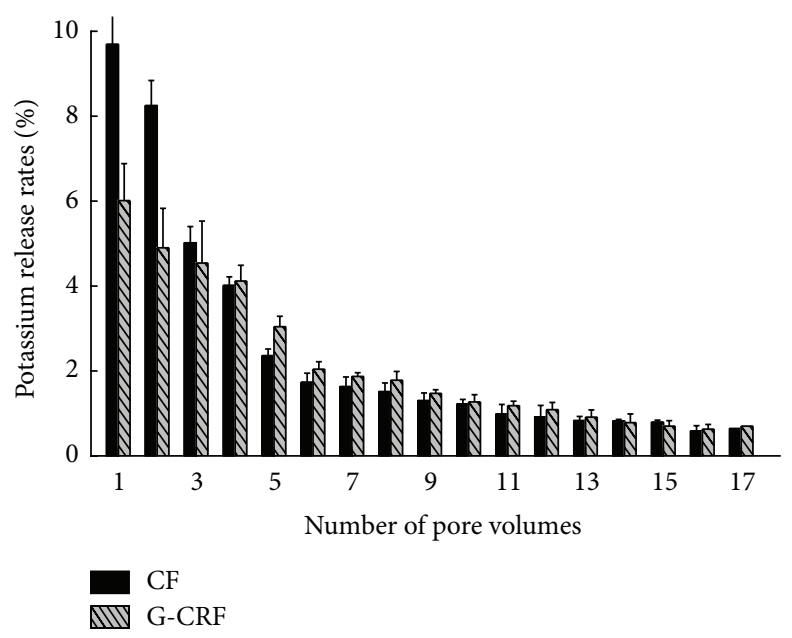

(c)

FIGURE 1: Nitrogen (a), phosphorus (b), and potassium (c) release rates of CF and G-CRF with different pore volumes.

solution in the bottle was filtered through the qualitative filter paper for determining $\mathrm{N}, \mathrm{P}$, and $\mathrm{K}$ contents. The nutrient determining and release rate calculating were done the same as in temperature experiment.

2.4. Analysis Methods. All of the solution samples were digested by $\mathrm{H}_{2} \mathrm{SO}_{4}-\mathrm{H}_{2} \mathrm{O}_{2}$ digestion for the measurement of $\mathrm{N}, \mathrm{P}$, and $\mathrm{K}$. $\mathrm{N}$ was determined by the micro-Kjeldahl methods [17], P by ascorbic-blue colorimetric methods [18], and $\mathrm{K}$ by flame photometry (model: EP-640, Shanghai, China).

2.5. Statistical Methods. All statistical analyses were performed with Statistical Analysis Systems SPSS 13.0 (SPSS for Windows, Version 13.0). The differences among the treatments were analyzed with ANOVA, and the differences reported throughout are significant at $P \leq 0.05$ or 0.01 . The nutrient release rates or patterns were described with function equations.

\section{Results}

3.1. Nutrient Release Rates of Fertilizers. Nutrient release rates of CF and G-CRF treatments are shown in Figure 1. On leaching experiment, the $\mathrm{CF}$ and G-CRF treatments displayed high $\mathrm{N}$ release rates of 32.6 and $24.0 \%$ of one pore volume, respectively, and then both decreased gradually with time (Figure $1(\mathrm{a})$ ). Before 4 pore volumes, the $\mathrm{N}$ release rates in the $\mathrm{G}$ CRF treatment were lower than that in CF treatment in each pore volume, especially from 1 to 2 pore volumes $(P<0.01)$. However, the results were reversed after 4 pore volumes; the $\mathrm{N}$ released rate of G-CRF exceeded that of CF; especially during 5 and 7 pore volumes the release rates of two fertilizer treatments showed obvious differences $(P<0.01)$, which indicated that the G-CRF had the effect of delaying the $\mathrm{N}$ release.

The $\mathrm{P}$ release rates of $\mathrm{CF}$ and G-CRF treatments are obviously lower relative to $\mathrm{N}$ release rates and also decreased with increasing leaching pore volume. The reason which caused the low release rate was poor mobility of $\mathrm{P}$ fixed by 


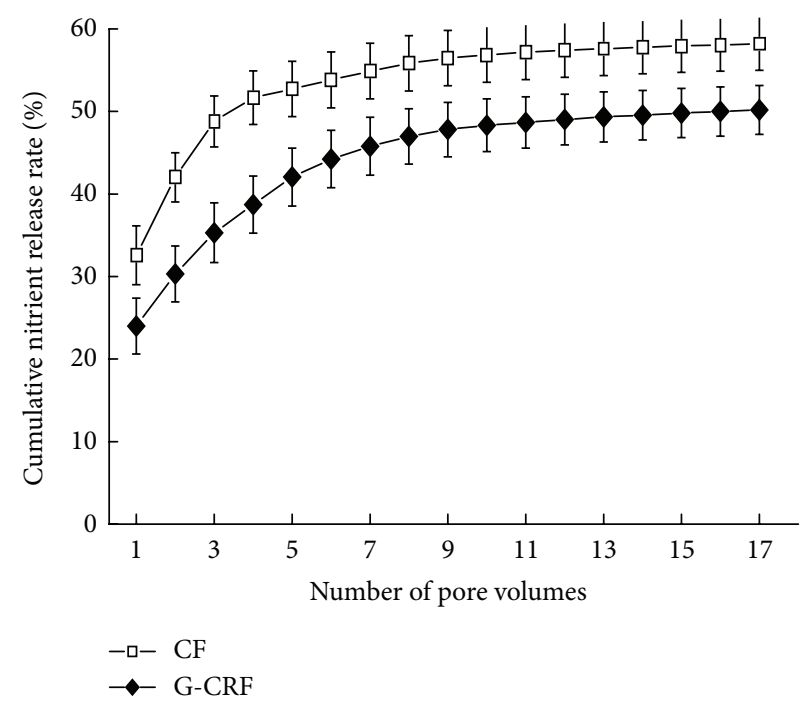

(a)

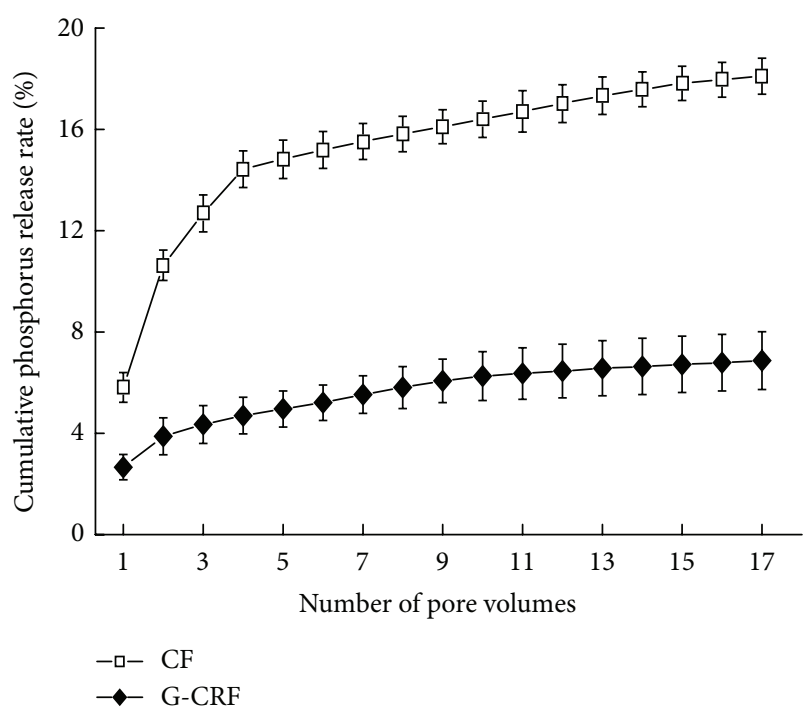

(b)

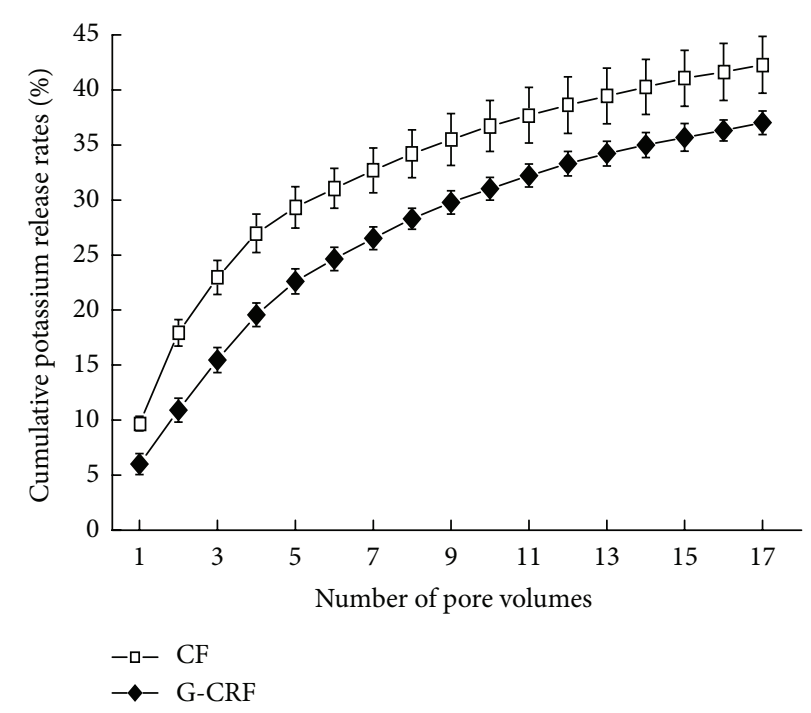

(c)

FIgure 2: Cumulative N (a), P (b), and $\mathrm{K}$ (c) release rates of CF and G-CRF with different pore volumes.

$\mathrm{Fe}^{3+}$ or $\mathrm{Al}^{3+}$ in red soils. During 4 pore volumes, especially from 1 to 2 pore volumes, relatively higher release rates were shown in both treatments, but the rates were 1.4-3.2\% lower in G-CRF than thatin CF during this period (Figure 1(b)), and the release rates had obvious differences between $C F$ and the G-CRF treatments $(P<0.01)$. After 4 pore volumes, the release rates in two treatments were all very low leaching of $P$ only under $0.39 \%$, but CF treatment was slightly higher than G-CRF treatment in each pore volume.

The curves of $\mathrm{K}$ release in CF and the G-CRF treatments were similar to $\mathrm{N}$ release. In 4 pore volumes, $\mathrm{K}$ release rates in the G-CRF treatment were lower than that in CF treatment (Figure $1(\mathrm{c})$ ), especially from 1 to 2 pore volumes; the rates reached significant differences $(P<0.01)$. While the situation is inversed from 4 to 17 pore volumes, the $K$ release rates of the G-CRF were relatively higher behind 4 pore volumes. The G-CRF had also obviously shown different effects with control release on $\mathrm{K}$. Overall, the release rates of $\mathrm{K}$ were much slower than $\mathrm{N}$ in each pore volume and a little faster than $\mathrm{P}$, which should be caused by the differences in characteristics of nutrient elements, adsorption, and fixation abilities of carrier materials to different nutrient ions.

Cumulative $\mathrm{N}$ release rates of G-CRF treatment were lower than CF treatment during the whole leaching experiment period (Figure 2(a)). During 4 pore volumes, the differences between fertilizer treatments increased with increasing leaching pore volume and reached the maximum value of 4 pore volumes with the $\mathrm{N}$ release rates of $51.7 \%$ in $\mathrm{CF}$ and $38.7 \%$ in the G-CRF treatments. However,the $\mathrm{N}$ release rate of G-CRF in each leaching pore volumehas exceeded that of $\mathrm{CF}$ after 4 pore volumes; this would reduce the differences of the cumulative release ratesbetween two treatments gradually with increasing number of pore volumes. At the end of the leaching experiment, the cumulative release rates were 
58.2 and $50.2 \%$ in CF and G-CRF treatments, respectively. Accumulative release rates displayed significant differences $(P<0.01)$ between CF and G-CRF treatments in whole leaching experiments.

Change of $\mathrm{P}$ cumulative release rate was shown in Figure 2(b). Until 4 pore volumes, cumulative release rate in CF treatment reached $14.4 \%$, while it reached only $4.7 \%$ in the G-CRF treatment. Due to the release rates which were slowly increased after 4 pore volumes, cumulative release rates of $\mathrm{P}$ were only 18.1 and $6.9 \%$ for CF and G-CRF treatments, respectively, at the end of whole leaching experiment, but it was also displaying significant differences $(P<0.01)$ between two treatments in all leaching pore volumes.

Potassium cumulative release rate in CF and the G-CRF treatments was similar to $\mathrm{N}$ release rate (Figures 2(a) and $2(c)$ ). The $\mathrm{K}$ cumulative release rate was also lower in the G-CRF treatment than that of CF treatment (Figure 2(c)). The differences of the $\mathrm{K}$ release rates between two fertilizer treatments reached the highest values of $27.0 \%$ and $19.6 \%$ for $\mathrm{CF}$ and the G-CRF treatments in 4 pore volumes. At the end of the leaching experiment, the cumulative release rates were 42.3 and $37.0 \%$ for $\mathrm{CF}$ and the G-CRF treatments, respectively, and the rates displayed significant differences $(P<0.01$ before 10 pore volumes and $P<0.05$ after 10 pore volumes) between both treatments in whole leaching period.

Based on NPK release curves of the G-CRF, the course of nutrient release could be divided into two periods, and 4 pore volumes could be recognized as the "turning point." Before 4 pore volumes, NPK release rates in the G-CRF were obviously slower than that in CF. But after 4 pore volumes the release rates in the G-CRF were relatively higher (except $\mathrm{P}$ nutrient) than that in CF, which indicated that the G-CRF had the effect of delaying the nutrient release. The patterns of NPK release rates in each phase of the CF and G-CRF could be better characterized by the power function. The cumulative nutrient release patterns of the CF and the G-CRFcould be fitted with exponentialfunction equations and logarithmic function equations, respectively (Table 1).

\subsection{Impact Factors Governing Nutrients Release from G-CRF.} It is commonly thought that soil moisture, temperature, soil $\mathrm{pH}$, and nutrient content are all important factors governing the nutrient release from fertilizer. Figure 3 showed that the $\mathrm{N}, \mathrm{P}$, and $\mathrm{K}$ cumulative release rates with different soil moistures all increased steadily, showing liner relationships with time $(P<0.05)$. The higher the soil moisture was, the greater the nutrient release rate was in each sampling time. The increasing soil moisture enhanced the nutrient release from the G-CRF. The nutrient release at the beginning had more obviously increased when the soil moisture exceeded $45 \%$ which caused oversaturated soil water. The release rates of NPK nutrients under different soil moisture treatments displayed in turn $75 \% \approx 105 \%>45 \%>25 \% \approx 35 \%>15 \%$ $(P<0.05)$. Therefore, higher soil moisture $(>45 \%)$ had less benefit to control nutrient release for a long period of time, which could result in the insufficiency of nutrient supply in the latter period of plant growth. Soil moisture of $45 \%$ could be a turning point of the effect on the nutrient release of the G-CRF because the soil would be oversaturated when exceeding the soil moisture, which was in favor of nutrient release from the G-CRF.

Cumulative release rates of the G-CRF under different temperatures were shown in Figure 4. Increase of temperature was in favor of release of $\mathrm{N}, \mathrm{P}$, and $\mathrm{K}$. The higher temperatures resulted in the higher release rates presented throughout the 15-day experiments. During the 15 days of incubated experiments of temperature effects, the changing tendency of $\mathrm{N}, \mathrm{P}$, and $\mathrm{K}$ release rates increased with increasing incubated time, but release patterns come out with certain differences, the $\mathrm{N}$ release rates were rather slow during first 4 days (Figure 4(a)), and they remained stationary in 4 to 6 days and then became fast rapidly after the 6th day. Phosphorus was relatively slowed before 9th $\mathrm{d}$ and then subsequently increased obviously (Figure 4(b)). Potassium release pattern showed a linear relationship (Figure 4(c)).

The $\mathrm{N}$ release rates found great differences among different temperature treatments. Before the 4th day, the released rates of $\mathrm{N}$ relatively were lower when the temperatures were lower than $15^{\circ} \mathrm{C}$, which were only 4.3 and $12.2 \%$ under $5^{\circ}$ and $15^{\circ} \mathrm{C}$, respectively. On the 4 th $\mathrm{d}$, it was released from 20.9 to $40.4 \%$ when the temperature was between $25^{\circ}$ and $55^{\circ} \mathrm{C}$. On the 15th day, the release rates of $\mathrm{N}$ reached 49.7 and $54.8 \%$ at $5^{\circ}$ and $15^{\circ} \mathrm{C}$ and 64.8 to $77.8 \%$ when the temperature ranges between $25^{\circ}$ and $55^{\circ} \mathrm{C}$ (Figure 4(a)). Phosphorous release rates were lower, only $30.8 \%$, when the temperature was below $25^{\circ} \mathrm{C}$, but the rates promptly increased when temperatures range between $35^{\circ}$ and $55^{\circ} \mathrm{C}$ and reached 44.8 to $64.8 \%$ (Figure $4(\mathrm{~b})$ ). Potassium release rate was the lowest with temperature of $5^{\circ} \mathrm{C}$, which was only $42.8 \%$ release at end of experiment. With increasing of temperature, the $\mathrm{K}$ release rates increased progressively, which were in the range of 58.6 to $84.8 \%$ with the other 5 treatments of $15^{\circ}$ to $55^{\circ} \mathrm{C}$ (Figure 4(c)).

Soil $\mathrm{pH}$ range from 4 to 9 covered the most soils $\mathrm{pH}$ worldwide. In Figure 5, release rates of N, P, and K showed the similar trend under different $\mathrm{pH}$ treatments; the release rates were slightly high at low and high $\mathrm{pH}$ treatments but did not show obvious differences in each incubation period $(P>0.05)$. Thus, after 15 days of incubation, the cumulative curves of NPK release rates looked like shape of a "u" letter pulled wide with the treatments of $\mathrm{pH}$ range from 4 to 9 , and the lower release rates appeared in that of $\mathrm{pH}$ 6-7 treatments (Figure 6). It indicated that the better-controlling effect of GCRF was displayed at soil weak acid or neutral $\mathrm{pH}$.

In order to study the relationship between nutrient contents in the G-CRF and its nutrient release rates, the release rates of $\mathrm{N}, \mathrm{P}$, and $\mathrm{K}$ from the G-CRFs with different nutrient contents were shown in Figure 7. Nitrogen release rate increased rapidly with increasing incubation time and then stabilized on the 12th d (Figure 7(a)). Courses of $\mathrm{N}$ release rates of $25-40 \%$ nutrient contents increased with increasing incubation period, showing linear relationship with significant level $(P<0.05)$ during the experimental period of 15 day. At the end of experiments, $\mathrm{N}$ release rates among the treatment of these nutrient contents reached 63.45 to $74.43 \%$.

Before the 9th day of incubation, $\mathrm{P}$ release rates of all the treatments increased slowly with time; after that, it presented 


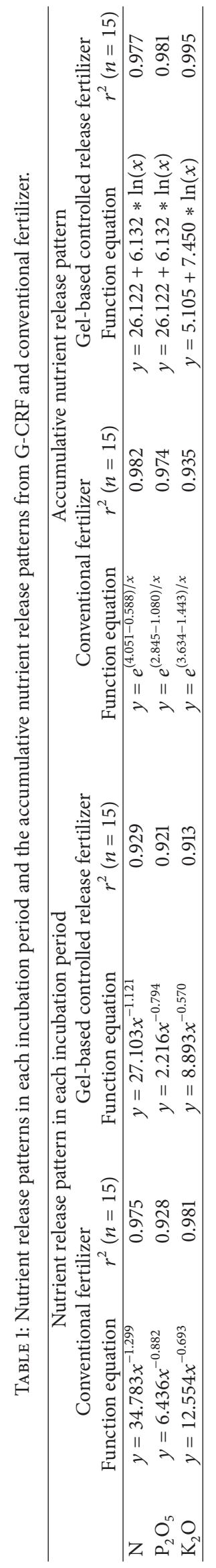




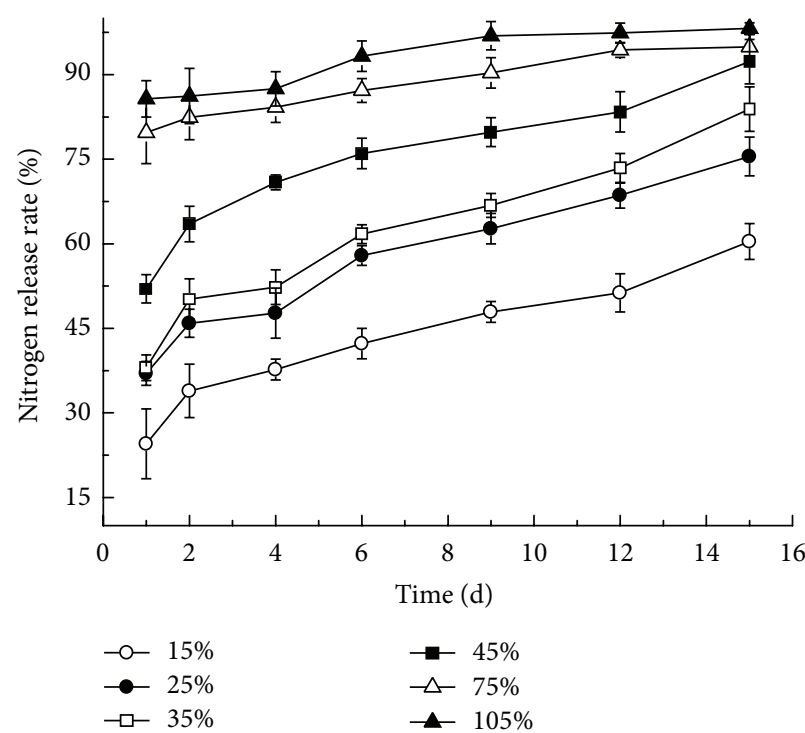

(a)

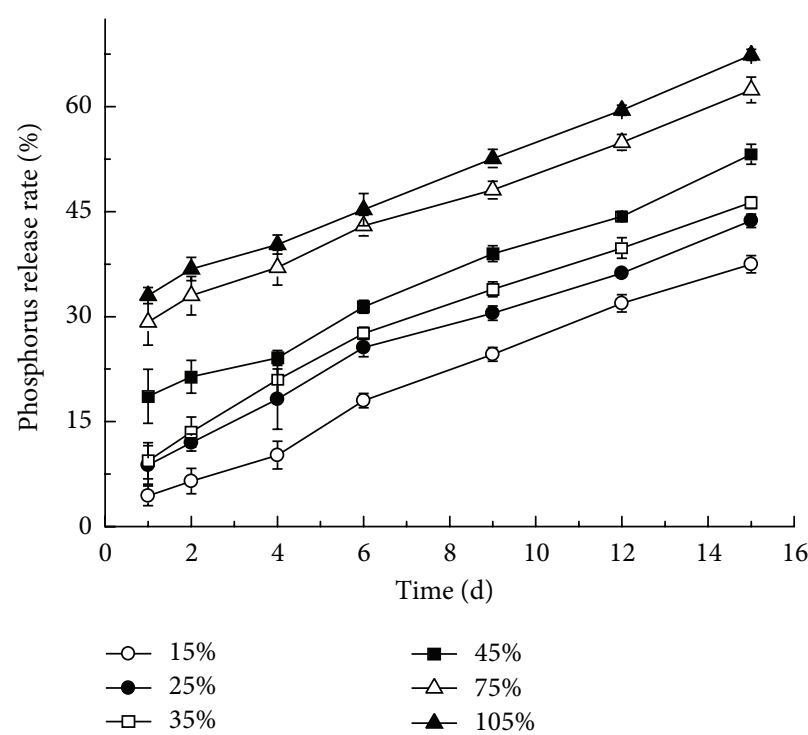

(b)

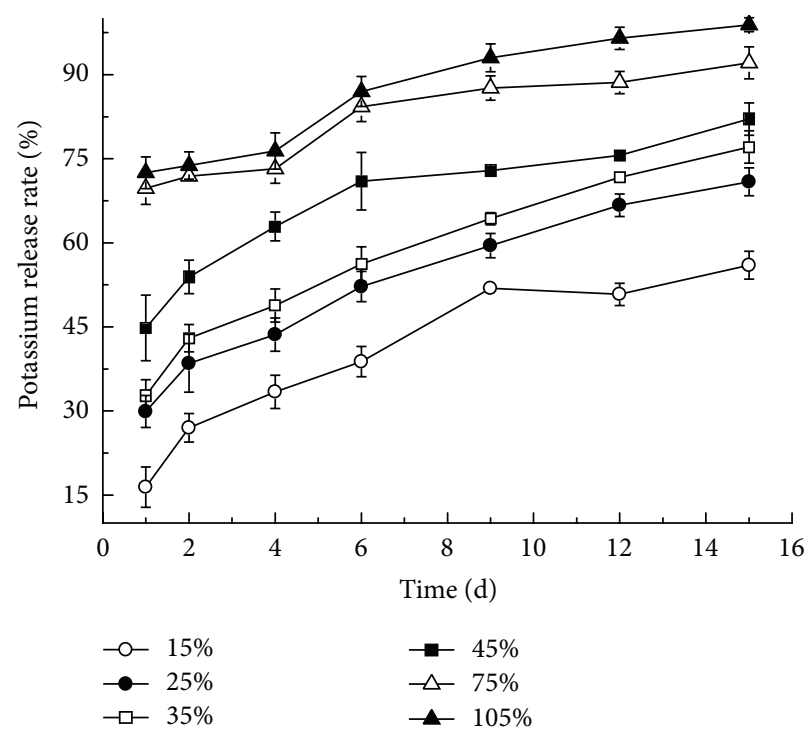

(c)

FIGURE 3: Release rates of N (a), P (b), and K (c) from G-CRF under different soil moistures.

rapid increases and reached 25.70 to $42.77 \%$ at the end of the incubation experiment (Figure 7(b)); the $\mathrm{P}$ is easily adsorbed by red soils which caused the slower release at the earlier period of experiment. The release rate of $\mathrm{K}$ showed a linear relationship; at the 15 th day, the release rates of $\mathrm{K}$ with different treatments can reach 57.8 to $73.1 \%$ (Figure $7(\mathrm{c})$ ).

The N, P, and K release rates showed positive relationship with respect to nutrient contents of the G-CRF. Higher nutrient contents in the G-CRFwould display the higher release rates from G-CRF systems; therefore, it could bethought that the lower nutrient contents in the G-CRF are more efficiently to control nutrient release. But the G-CRF with low nutrient contents, needing more amount of organic polymer materials which were used, increased the cost of the fertilizer due to the higher prices of organic polymer materials. Therefore, it was recommended that the suitable nutrient contents in the GCRF were 30 to $35 \%$, which comprehensively considered the nutrient release rate and economic cost of the fertilizer.

\section{Discussion}

Study and development of CRF are still strategic to improve nutrient use efficiency of chemical fertilizers in a long time in the future, and more new types of CRF could be developed. But low cost, better-controlling effect, being environmentfriendly, and high benefit are the key factors which limited CRFs applied to field crops more widely. Thus, the controlled release mechanism, carrier materials, and processing technology would be paid more attention for development of CRFs by researchers [19]. The gel-based controlled release 


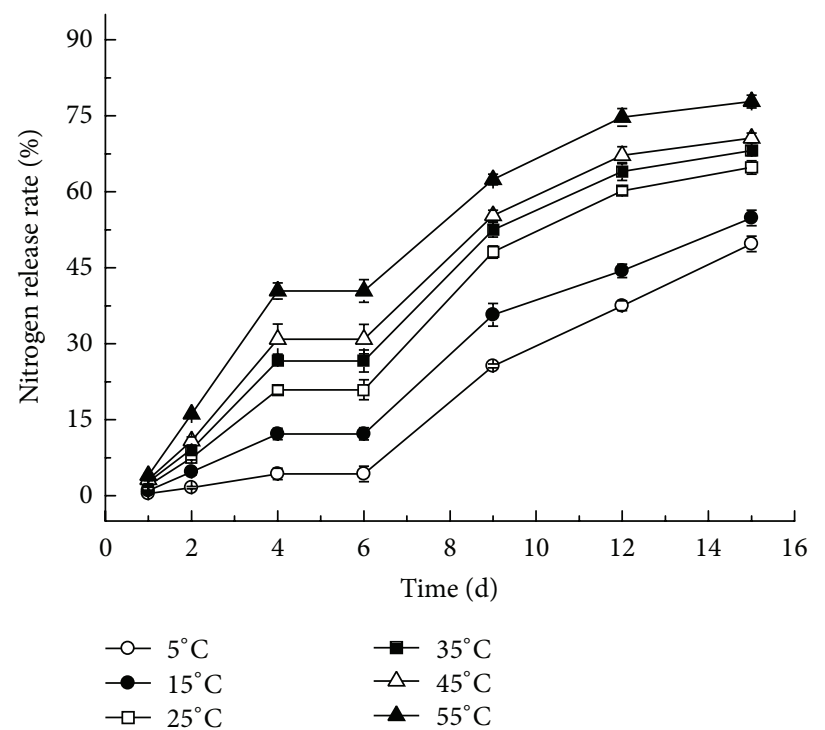

(a)

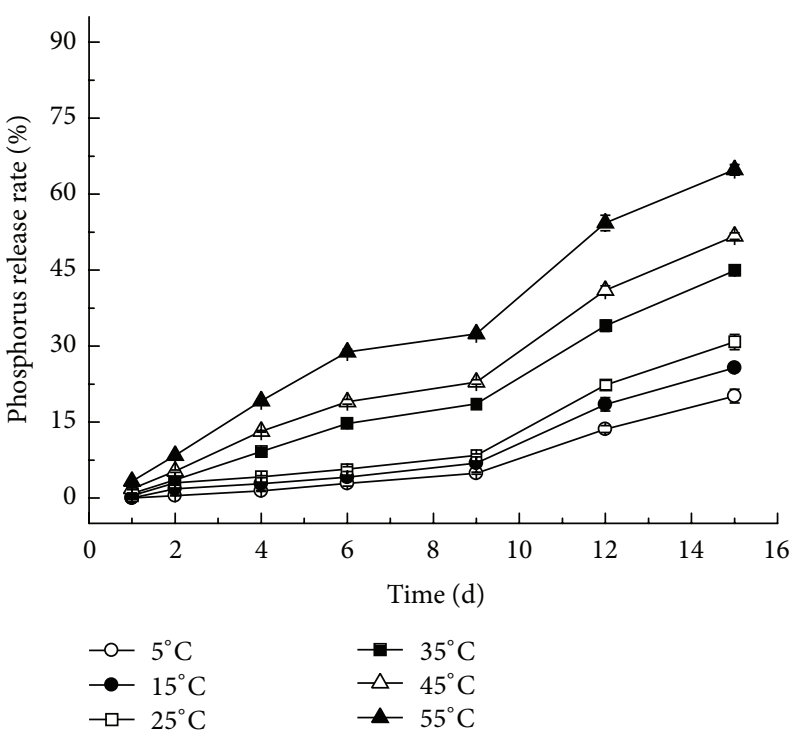

(b)

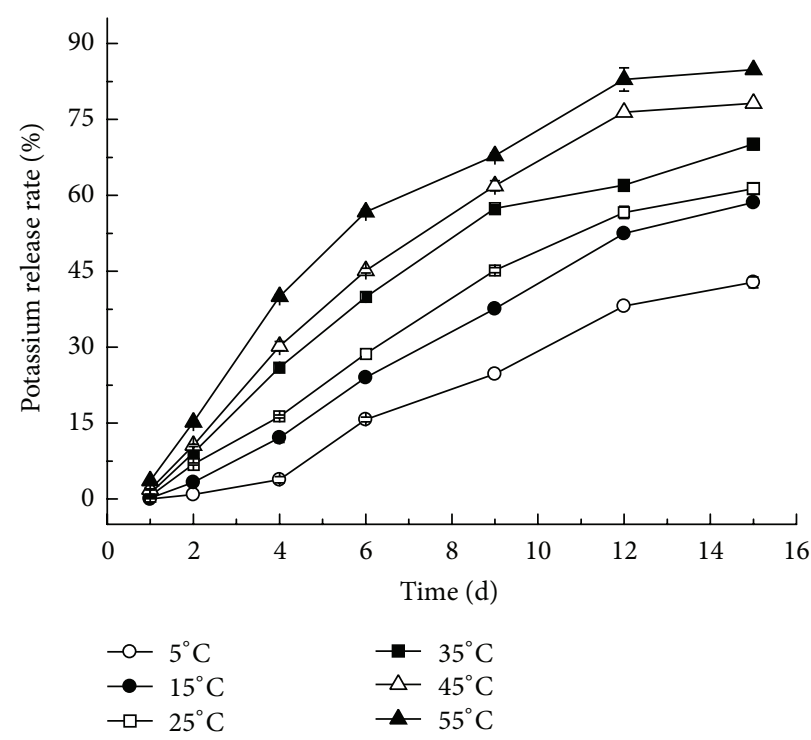

(c)

Figure 4: Release rates of $\mathrm{N}(\mathrm{a}), \mathrm{P}(\mathrm{b})$, and $\mathrm{K}$ (c) from G-CRF under different temperatures.

fertilizer (G-CRF) was a new type of controlled release fertilizer, and several researchers have conducted research work $[6,20]$; however the G-CRFs are still being developed. Although no G-CRF products were applied widely to field crops, this is one of development directions of the CRFs. The G-CRF has also shown better effect on controlling nutrient release in this experiment and other verification tests [10-12].

The CRFs have a variety of nutrient release mechanisms. These mechanisms include controlled water solubility of the material by semipermeable coatings, occlusion, protein materials, or other chemical forms, by slow hydrolysis of water-soluble low molecular weight compounds or by other unknown means [19]. The G-CRF was different from coated controlled release fertilizer and organic synthesis of slightly soluble type of slow release fertilizer in nutrient release mechanisms. The nutrient release from coated fertilizer was one kind of physical controlled type of CRF, which is mainly controlled by diffusion mechanism. The release course of coated CRFs contains 3 distinct stages, including a lag period, a constant-release rate, and a stage of gradual decay of release rate [21]. These organic syntheses of slightly soluble type of slow release fertilizer were by chemical or biological degradation. The nutrient release course of G-CRF was permeated by water soak, and it was considered that G-CRF was one of the physical controlled types of CRFs produced by the integral method [22], but the controlled release mechanism of the G-CRF in this experiment was mainly physical and partly chemical processes, which not only has the physical obstructive effect of gel-carrier composites but also has chemical ion-changing or adsorbing effect of the composites. 

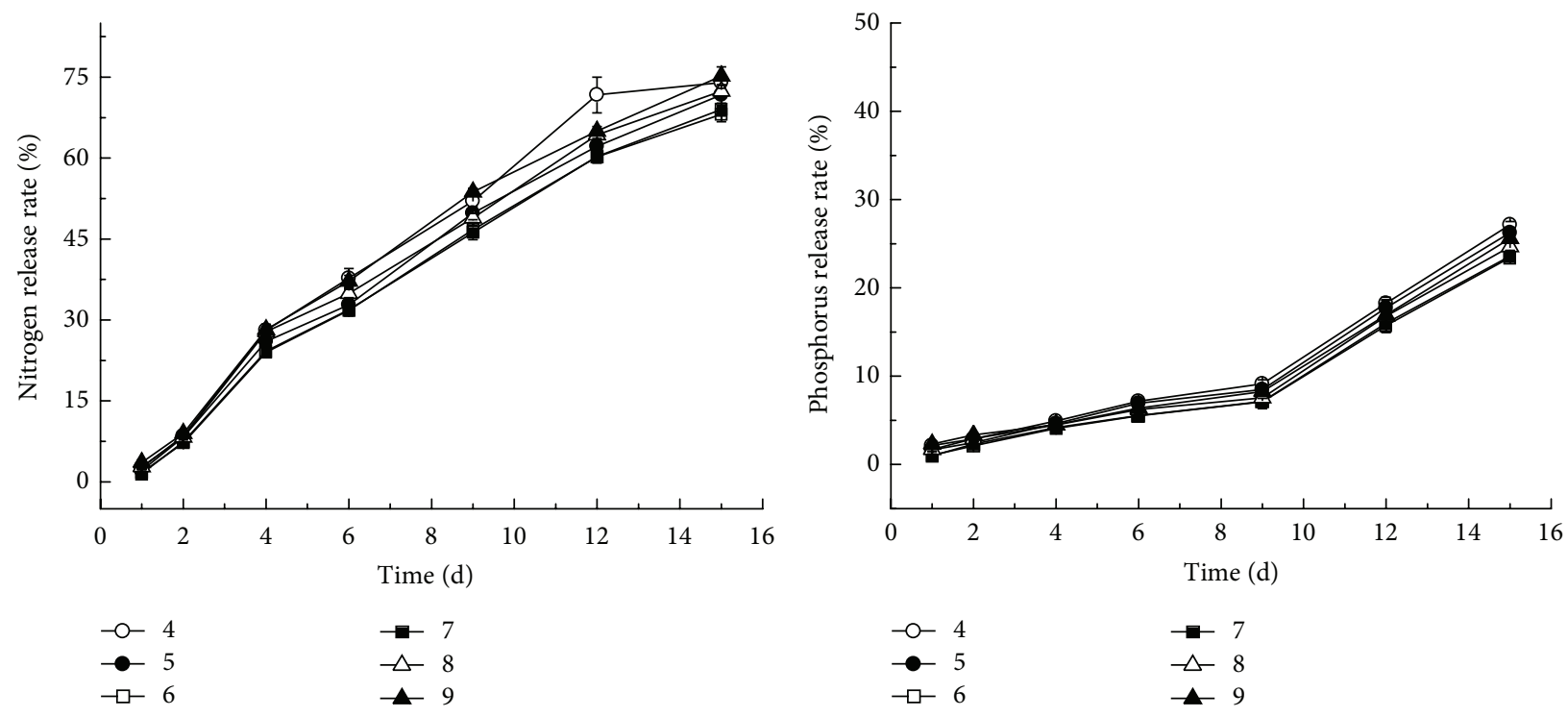

(a)

(b)

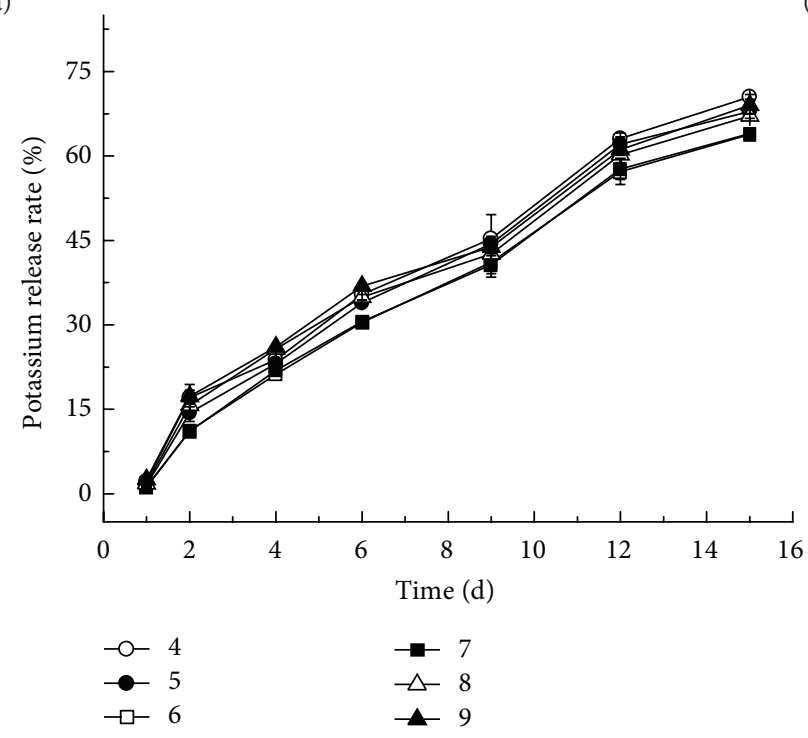

(c)

Figure 5: Release rates of N (a), P (b), and K (c) from G-CRF under different soil pH values.

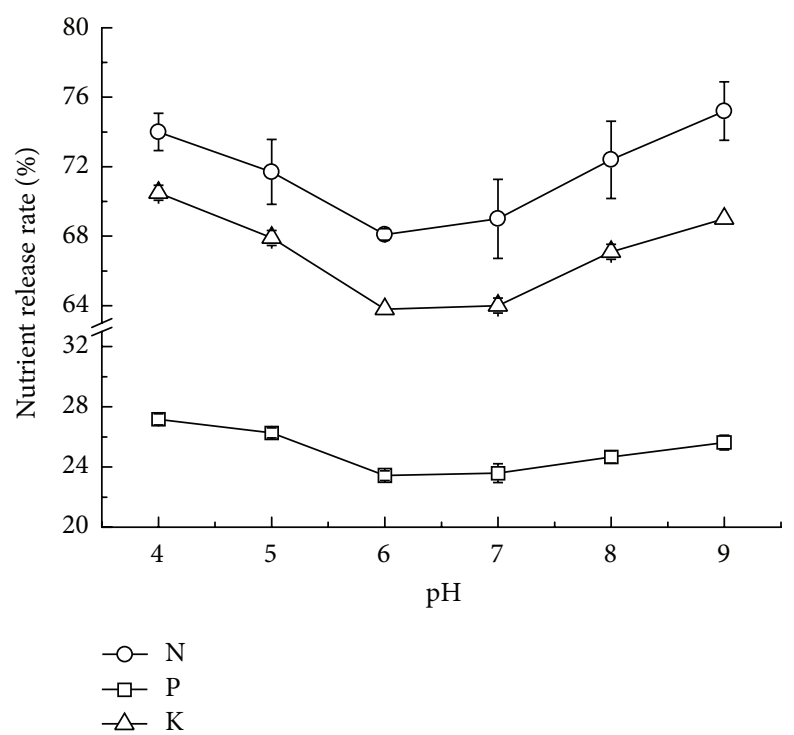

FIGURE 6: Cumulative release rates of $\mathrm{N}, \mathrm{P}$, and $\mathrm{K}$ from $\mathrm{G}-\mathrm{CRF}$ under different $\mathrm{pH}$ at end of the 15th $\mathrm{d}$ incubation time. 


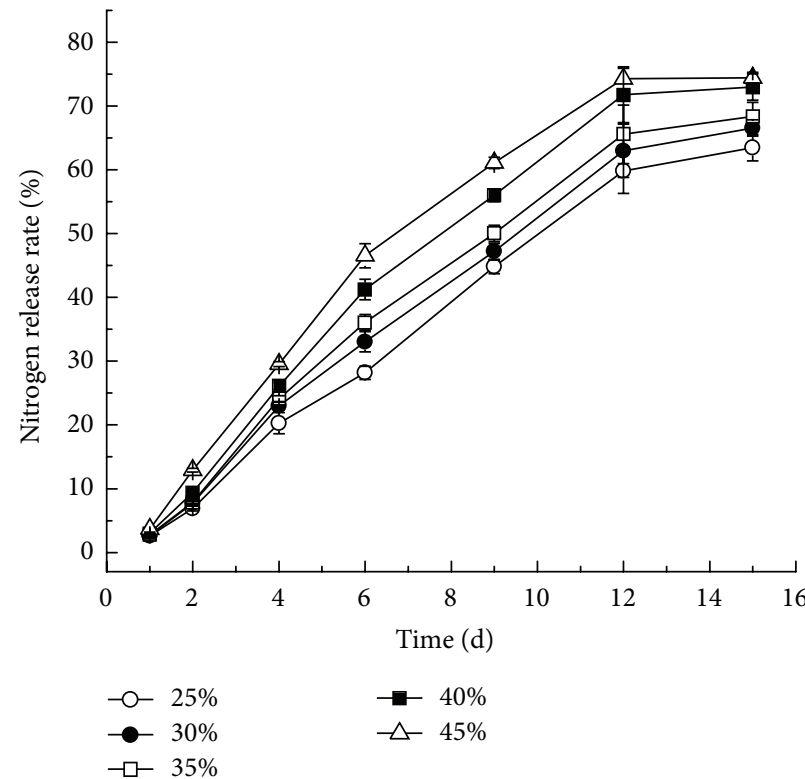

(a)

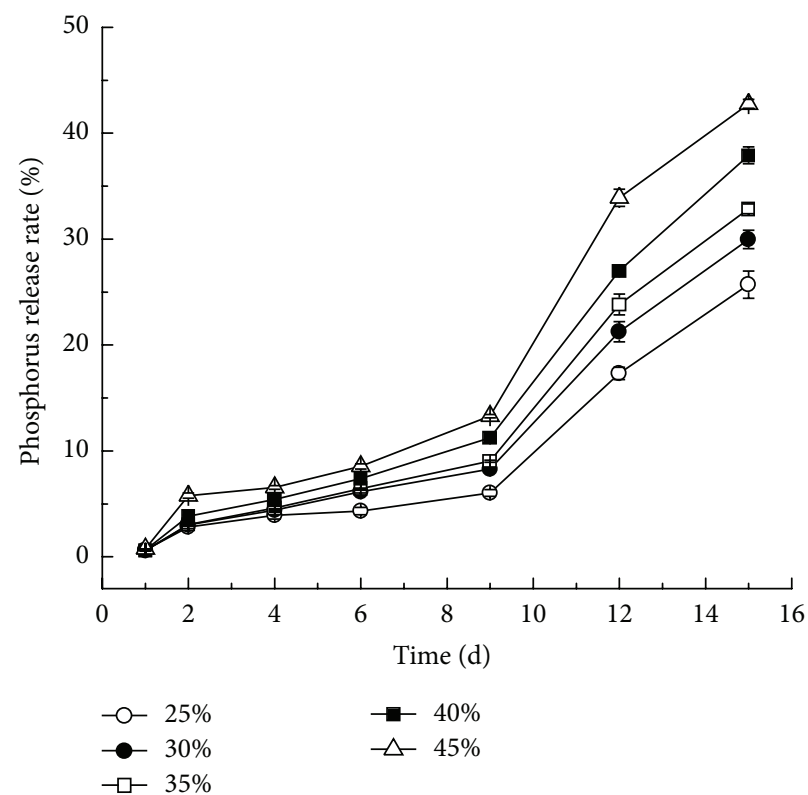

(b)

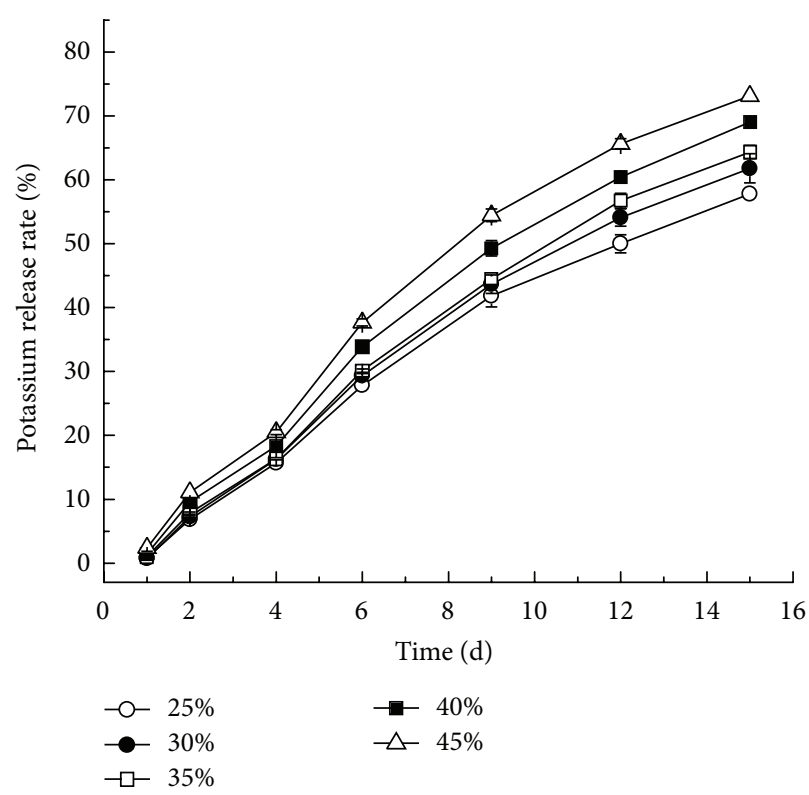

(c)

FIgURE 7: Release rates of N (a), P (b), and K (c) from G-CRFs with different nutrient contents.

The G-CRF displayed lower N, P, and $\mathrm{K}$ nutrient release rates than $\mathrm{CF}$, due to gel-carrier materials preventing physically from nutrient release before 4 pore volumes of incubation, and then higher $\mathrm{N}$ and $\mathrm{K}$ release rates than that of $\mathrm{CF}$, due to loosing fertilizer particles after that time. But the total release rates of $\mathrm{N}, \mathrm{P}$, and $\mathrm{K}$ in the G-CRF were lower, 8.0, 11.2, and $5.3 \%$, than that in $\mathrm{CF}$ in whole incubation experiment, respectively, which could result in $\mathrm{NH}_{4}{ }^{+}, \mathrm{K}^{+}$, and $\mathrm{PO}_{4}{ }^{-3}$ absorbed partly by gel-carrier composites, because of these compounds possessing high ionic exchanges [23].

Complicated field soil conditions have significant influences on the nutrient release of fertilizer; for example, temperature, water content, soil texture, soil $\mathrm{pH}$, ion exchange capacity of soil, the activity of soil microbe, and soil organic matter were all the important impact factors which affect the nutrient release rate, and the effect of each factor was different for a certain CRF [24-27]. It was necessary to fully consider the water content, temperature, $\mathrm{pH}$ of soil, and so forth, for a veracious estimate of different CRFs. The temperature was regarded as the most important factor in the nutrient release of CRFs [28], which was caused by the characters of coated material in the coated fertilizer [24]. However, by this GCRF, both temperature and soil moisture were main factors to affect nutrient release rate which would affect dispersion of 
fertilizer granules, effective cross section area of ion diffusion, and other physical/chemical processes in soil. In fact, by the CRFs in which a physical barrier controls the release easily affected by both soil moisture and temperature, such results have been tested in some studies and indicated that the nutrient releases rates of CRFs increased with improvement of the soil moisture and temperature [29-32]. In this experiment, the G-CRF showed obviously delaying release effects when soil moisture and temperature were below $45 \%(\mathrm{w} / \mathrm{w})$ and $35^{\circ} \mathrm{C}$, respectively. But the soil $\mathrm{pH}$ is slightly effective on nutrient release rate.

The gel-carrier materials could be selected from a wide range of natural, seminatural, and artificial synthesis organic materials, but the price of gel-carrier materials must be attended. More carrier materials were added into G-CRF; the cost of G-CRF was higher. Thus, it is necessary to consider comprehensively both the cost of materials and the effects of controlling nutrient release of G-CRFs, because high fertilizer price was main reason limited G-CRF applied widely to field crops, except selecting more cheap and effective materials and being used in G-CRF.

There are some problems which still exist and need to be resolved in further study. The gel-carrier materials can be chosen in a more diversiform in order to get a much better control effect, which made the gel-based CRF much practical and to get more benefit. The effect of the G-CRF on the soil physicochemical properties and change of soil nutrients need to be studied through more field experiments. Furthermore, the mechanism of nutrient controlled release from the GCRF in field soil and its agronomic benefit merit to be further study.

\section{Competing Interests}

The authors declare that they have no competing interests.

\section{Acknowledgments}

The authors thank the Fujian Provincial Department of Science and Technology, China (Grant nos. 2014R1022-4 and 2002N002), and China tobacco companies, Fujian Company, China (Grant no. 2012-045), for their financial support.

\section{References}

[1] J. R. Elliot and T. R. Fox, "Effects of a controlled release fertilizer on the nitrogen dynamics of mid-rotation loblolly pine plantation in the piedmont, Virginia," in Proceedings of the 13th Biennial Southern Silvicultural Research Conference, K. F. Connor, Ed., p. 640, US Department of Agriculture, Forest Service, Southern Research Station, Asheville, NC, USA, 2006.

[2] A. Shaviv, "Advances in controlled-release fertilizers," Advances in Agronomy, vol. 71, pp. 1-49, 2001.

[3] J. E. Pack, C. M. Hutchinson, and E. H. Simonne, "Evaluation of controlled-release fertilizers for northeast Florida chip potato production," Journal of Plant Nutrition, vol. 29, no. 7, pp. 13011313, 2006.

[4] K. Lubkowski and B. Grzmil, "Controlled release fertilizers," Polish Journal of Chemical Technology, vol. 9, no. 4, pp. 81-84, 2007.
[5] S. P. Landels, "Global update on slow-release fertilizers," in Proceedings of the 53rd Annual Meeting of the Fertilizer Industry Round Table, Winston-Salem, NC, USA, October 2003.

[6] U. Shavit, A. Shaviv, G. Shalit, and D. Zaslavsky, "Release characteristics of a new controlled release fertilizer," Journal of Controlled Release, vol. 43, no. 2-3, pp. 131-138, 1997.

[7] J. J. Mortvedt and J. J. Kelsoe, "Crop response to ferrous sulfate in banded gel of hydrophilic polymers," Soil Science Society America Journal, vol. 56, no. 4, pp. 1319-1324, 1992.

[8] R. L. Mikkelsen, "Using hydrophilic polymers to improve uptake of manganese fertilizers by soybeans," Fertilizer Research, vol. 41, no. 2, pp. 87-92, 1995.

[9] Z. J. Wu and L. J. Chen, Slow/Controlled Fertilizer: Principle and Application, Science Press, Beijing, China, 2003.

[10] H. Ding, Y. S. Zhang, S. J. Qin, W. H. Li, and S. Q. Li, "Effects of ${ }^{15}$ Nitrogen-labeled gel-based controlled release fertilizer on dry-matter accumulation and the nutrient-uptake efficiency of corn," Communications in Soil Science and Plant Analysis, vol. 42, pp. 1594-1605, 2011.

[11] Y. S. Zhang, H. Ding, C. S. Lu, W. H. Li, and L. Chen, "Effect of controlled release fertilizers on the yield and quality of peanut and nutrient use efficiency," Plant Nutrition and Fertilizer Science, vol. 13, pp. 700-706, 2007.

[12] X. Q. Zheng, H. Ding, Y. S. Zhang, X. T. He, and Z. C. Hong, "Effects of supported controlled release fertilizers on maize," Crops, vol. 5, pp. 82-85, 2011.

[13] J. J. Du, X. Y. Mao, and Z. W. Liao, "Effect of different media on N release characteristics of controlled/slow-release fertilizers," Journal of South China Agricultural University (Natural Science Edition), vol. 23, pp. 71-78, 2002.

[14] D. P. Li, X. C. Xu, and H. B. Wang, "The survey of the standard about the slow/controlled release fertilizer in the world," Phosphorus and Compound Fertilizer, vol. 20, pp. 41-42, 2005.

[15] M. L. Jackson, Soil Chemical Analysis, University of Wisconsin, Madison, Wis, USA, 2nd edition, 1979.

[16] C. L. Liu, M. K. Wang, and C. C. Yang, "Determination of cation exchange capacity by one-step soil leaching column method," Communications in Soil Science and Plant Analysis, vol. 32, no. 15-16, pp. 2359-2372, 2001.

[17] Y.-H. Chen, M.-K. Wang, G. Wang, M.-H. Chen, D. Luo, and $\mathrm{R}$. Li, "Nitrogen runoff under simulated rainfall from a sewageamended lateritic red soil in Fujian, China," Soil and Tillage Research, vol. 123, pp. 35-42, 2012.

[18] F. S. Watanabe and S. R. Olsen, "Test of an ascorbic acid method fro determining phosphorus in water and $\mathrm{NaHCO}_{3}$ extracts from soils," Soil Science Society America Journal, vol. 29, no. 6, pp. 677-678, 1965.

[19] M. E. Trenkel, Slow- and Controlled-Release and Stabilized Fertilizers: An Option for Enhancing Nutrient Use Efficiency in Agriculture, International Fertilizer Industry Association (IFA), Paris, France, 2nd edition, 2010.

[20] C. W. Du, J. M. Zhou, H. Y. Wang, and S. T. Li, "Preliminary study on the natural matrix materials for controlled release nitrogen fertilizer," Pedoshpere, vol. 14, pp. 45-52, 2004.

[21] A. Shaviv, S. Raban, and E. Zaidel, "Modeling controlled nutrient release from polymer coated fertilizers: diffusion release from single granules," Environmental Science and Technology, vol. 37, no. 10, pp. 2251-2256, 2003.

[22] H. B. Yin and Y. L. Shi, "The present situation and progress on the research of controlled release fertilizers," Chinese Journal of Soil Science, vol. 36, pp. 422-425, 2005. 
[23] J. A. Entry and R. E. Sojka, "Matrix-based fertilizer reduce nutrient leaching while maintaining Kentuchy bluegrass growth," Water, Air and Soil, vol. 207, no. 1, pp. 181-193, 2010.

[24] J. J. Oertli and O. R. Lunt, "Controlled release of fertilizer minerals by incapsulating membranes: I. Factors influencing the rate of release," Soil Science Society America Journal, vol. 26, pp. 579-583, 1962.

[25] M. Kochba, S. Gambash, and Y. Avnimelech, "Studies on slow release fertilizers: 1. Effects of temperature, soil moisture, and water vapor pressure," Soil Science, vol. 149, no. 6, pp. 339-343, 1990.

[26] C. E. Husby, Influence of temperature and time on nutrient release patterns of Osmocote Plus ${ }^{\mathrm{TM}}$, Nutricote ${ }^{\mathrm{TM}}$, and Polyon ${ }^{\mathrm{TM}}$ controlled-release fertilizers [M.S. thesis], Faculty of Virginia Polytechnic Institute and State University, Blacksburg, Va, USA, 2000.

[27] H. J. Zhang, Z. J. Wu, W. J. Liang, and H. T. Xie, "Research advances on controlled-release mechanisms of nutrients in coated fertilizers," Chinese Journal of Applied Ecology, vol. 14, no. 12, pp. 2337-2341, 2003.

[28] K. T. Morgan, K. E. Cushman, and S. Sato, "Release mechanisms for slow- and controlledrelease fertilizers and strategies for their use in vegetable production," HortTechnology, vol. 19, no. 1, pp. 10-12, 2009.

[29] J. H. Chen, Y. P. Cao, H. Xu, Z. G. Fang, and D. R. Mao, "Appraisal of nitrogen releasing characteristics of organic polymer coating controlled-release fertilizer," Plant Nutrient and Fertilizer Science, vol. 8, pp. 44-47, 2002.

[30] D. O. Huett and B. J. Gogel, "Longevities and nitrogen, phosphorus, and potassium release patterns of polymer-coated controlled-release fertilizers at $30^{\circ} \mathrm{C}$ and $40^{\circ} \mathrm{C}$," Communications in Soil Science and Plant Analysis, vol. 31, no. 7-8, pp. 959973, 2000.

[31] O. R. Lunt and J. J. Oertli, "Controlled release of fertilizer minerals by encapsulating membranes. II: efficiency of recovery, influence of soil moisture, mode of application and other consideration related to use," Soil Science Society of America Journal, vol. 26, pp. 584-587, 1962.

[32] J. Xiao, S. X. Zheng, and G. Y. Yi, "Kinetics and mechanism of nutrient release from controlled release fertilizer-part 3: effect of soil in moisture content on nutrient release of filmcoated controlled release fertilizer," Phosphorus and Compound Fertilizer, vol. 17, pp. 9-12, 2002. 

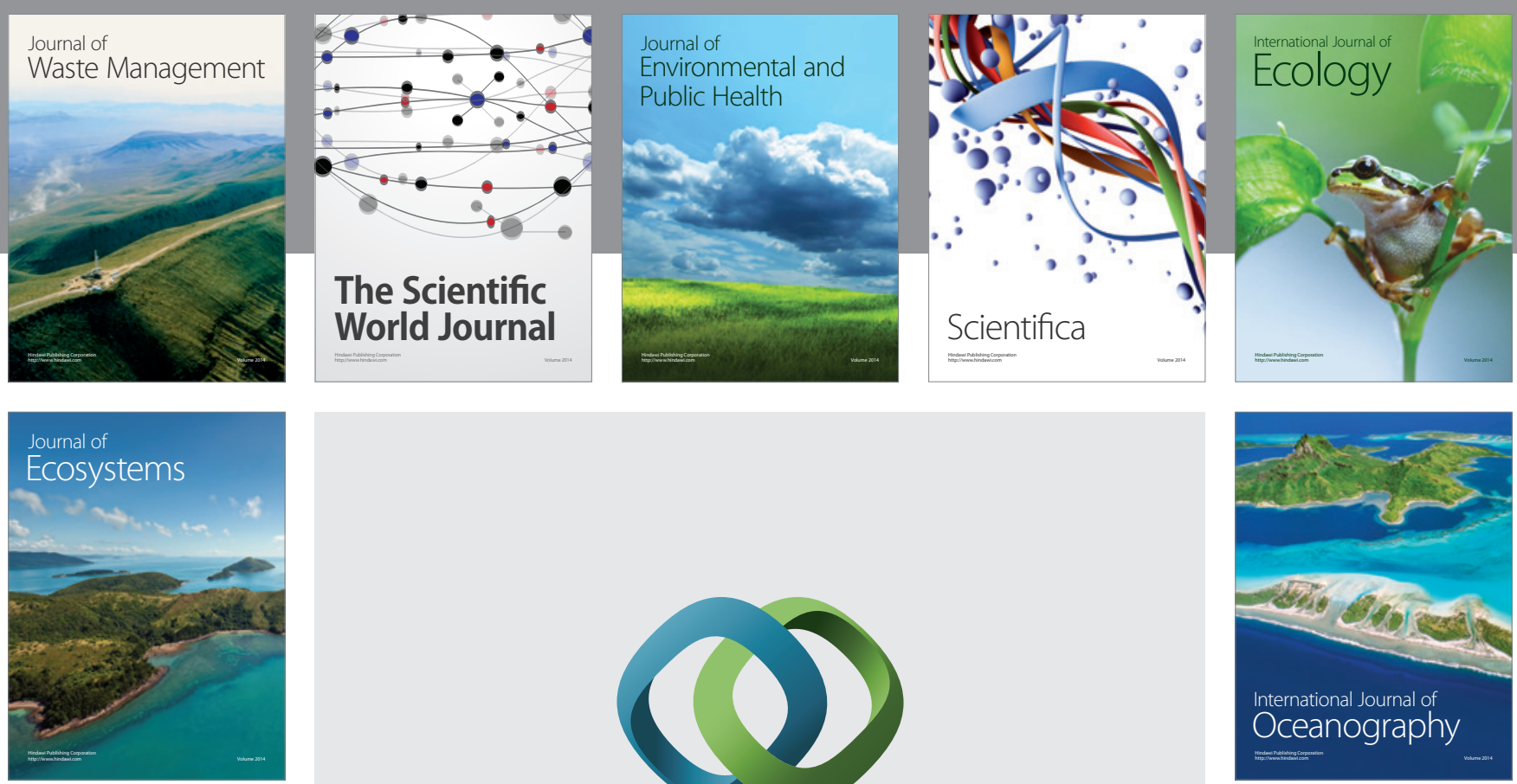

The Scientific World Journal
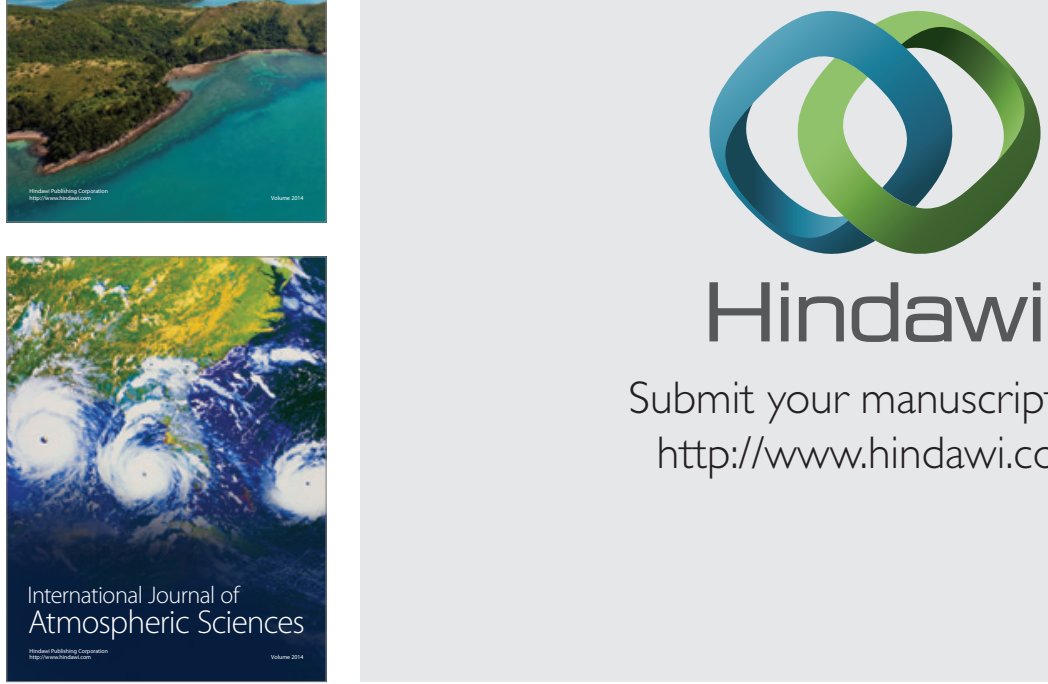

\section{Hindawi}

Submit your manuscripts at

http://www.hindawi.com
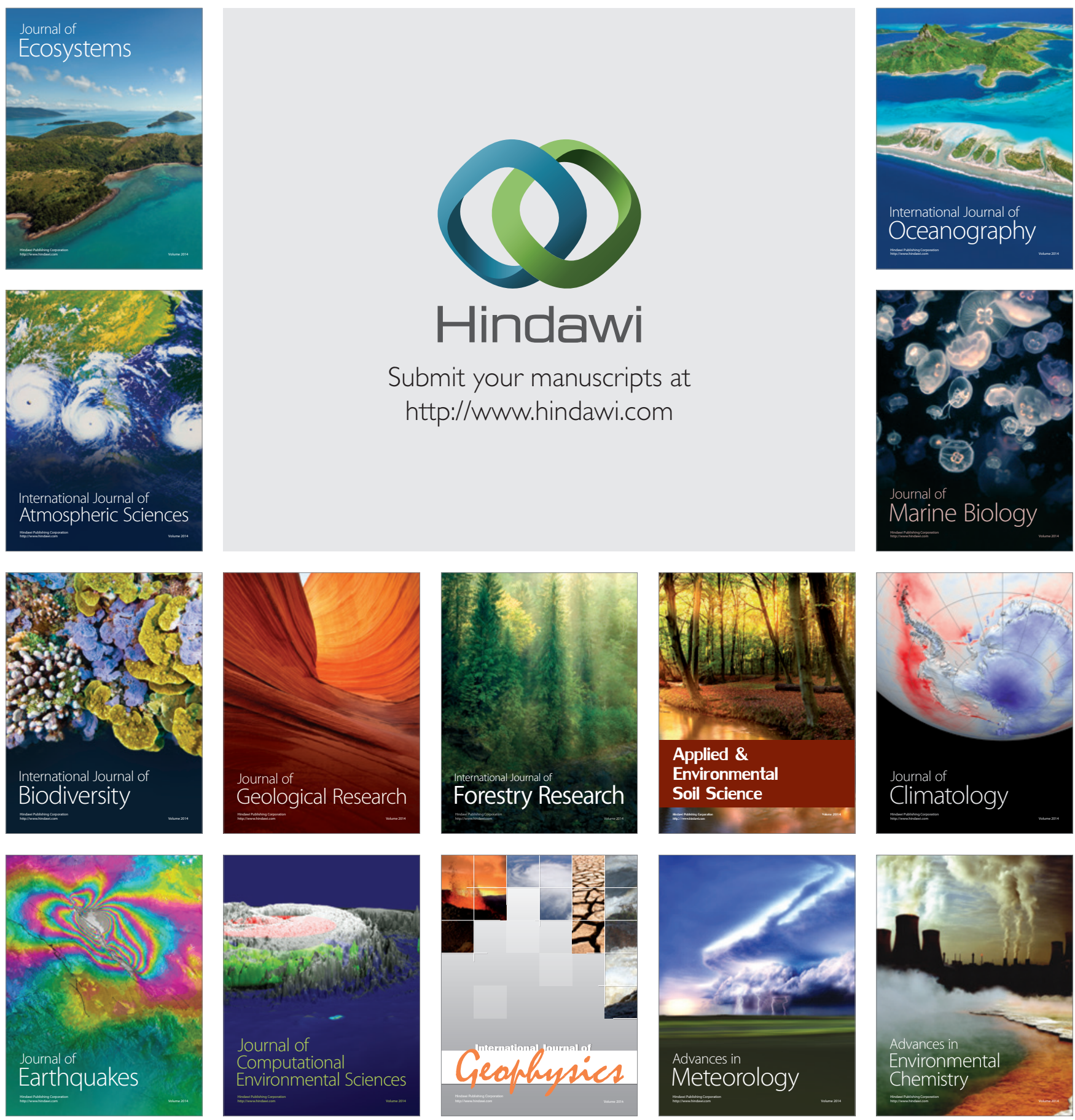